\title{
The epidemiology of fractures in Denmark in 2011
}

\author{
J. H. M. Driessen ${ }^{1,2,3}$ • L. Hansen ${ }^{4}$ - S. A. Eriksen ${ }^{5}$ - H. A. W. van Onzenoort ${ }^{3,6}$ •

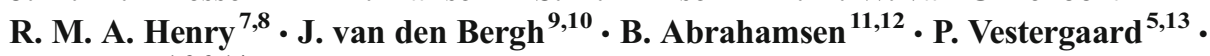 \\ F. de Vries ${ }^{1,2,3,14}$
}

Received: 9 October 2015 / Accepted: 7 January 2016/Published online: 4 February 2016

(C) The Author(s) 2016. This article is published with open access at Springerlink.com

\begin{abstract}
Summary In the present study, we used national health care databases to estimate fracture incidence rates (IRs) and compared these IRs based on imputed data. We showed that imputation could lead to both over- and underestimation of IRs, and future research should therefore focus on how to improve those imputations.

Introduction Osteoporosis is a major public health burden through associated (osteoporotic) fractures. In Denmark, the incidence rates (IRs) of hip fracture are widely available. However, there is limited data about other fracture sites. A recent report could only provide imputed IRs, although nationwide data is readily available in electronic healthcare databases. Therefore, our aim was to estimate fracture site-specific IRs for Denmark in 2011 and to compare those to the previously reported imputed data.
\end{abstract}

F. de Vries

frank.de.vries@mumc.nl

1 Division of Pharmacoepidemiology and Clinical Pharmacology, Utrecht Institute of Pharmaceutical Sciences,

Utrecht, The Netherlands

2 Care and Public Health Research Institute (CAPHRI), Maastricht, The Netherlands

3 Department of Clinical Pharmacy and Toxicology, Maastricht University Medical Centre+, Maastricht, The Netherlands

4 Danish Centre for Healthcare Improvements, Department of Business and Management, Aalborg University, Aalborg, Denmark

5 Department of Clinical Medicine, Aalborg University, Aalborg, Denmark

6 Department of Pharmacy, Radboud University Nijmegen Medical Centre, Nijmegen, The Netherlands
Methods Data from the Danish National Hospital Discharge Register was used to estimate age- and gender-specific IRs for any fracture as well as for different fracture sites in the Danish population aged 20 years and older in 2011. Hip fracture IRs were stratified to sub-sites, and IRs were determined for all hip fractures which were confirmed by surgery.

Results The total number of incident fractures in 2011 was 80 , 760 (IR 191, $95 \%$ confidence interval (CI) 190-192 (per 10, 000 person-years)), of which 35,398 (43.8\%, IR 171, $95 \%$ CI $169-173)$ occurred in men and 45,362 (56.2\%, IR 211, $95 \%$ CI 209-213) in women. The majority of the fractures occurred in the population aged 50 years and older $(n=50,470$, IR 249 , $95 \%$ CI 247-251). The numbers of any hip fracture were lower than the previously imputed estimates, whereas the number of forearm fractures was higher.

Conclusion We showed age- and gender-specific fracture rates for any fracture as well as for different fracture sites.

7 Department of Medicine, Maastricht University Medical Centre+, Maastricht, The Netherlands

8 Cardiovascular Research Institute Maastricht, Maastricht University Medical Centre+, Maastricht, The Netherlands

9 Department of Internal Medicine, Maastricht University Medical Centre, Maastricht, The Netherlands

10 Biomedical Research Institute, University Hasselt, Hasselt, Belgium

11 Odense Patient Data Explorative Network, Institute of Clinical Research, University of Southern Denmark, Odense, Denmark

12 Department of Medicine, Holbaek Hospital, Holbaek, Denmark

13 Department of Endocrinology, Aalborg University Hospital, Aalborg, Denmark

14 MRC Epidemiology Lifecourse Unit, Southampton General Hospital, Southampton, UK 
The IRs of most fracture sites increased with age. Estimating the number of fractures for Denmark based on imputation of data from other countries led to both over- and underestimation. Future research should therefore focus on how to improve those imputations as not all countries have nationwide registry data.

Keywords Epidemiology $\cdot$ Fractures $\cdot$ Incidence rates · Osteoporosis

\section{Introduction}

Osteoporosis is a major public health burden through associated (osteoporotic) fractures. In 2010, an estimated number of 66,000 incident fractures (12,000 hip fractures) occurred in the Danish population aged 50 years and older [1]. The associated costs of osteoporosis were estimated at $€ 1055$ million for Denmark, 2010 [1]. The estimated costs of osteoporotic fractures have been projected to increase by about $50 \%$ in 2025 due to ageing of the population [2].

An increasing number of studies have shown that secular trends in the incidence of hip fractures have levelled off or started to decline [3, 4]. A call to update the data for as many countries as possible has been made [3]. Hip fracture incidence rates (IRs) have been estimated in different periods for the Danish population [5, 6], and IRs of distal forearm fracture are available for the period 1976-1984 [7] and for 2010 [8].

The International Osteoporosis Foundation (IOF) estimated the country-specific burden of osteoporosis and the number of incident fractures in 2010 for individuals aged 50+ in Denmark [1]. Danish hip fracture IRs for 2004 were available from health registries which contain data on both in- and outpatient treatments [9]. IRs for other fracture sites were not available and, therefore, Swedish data from 1987 to 1994 were used [10]. All radiography referrals that come to medical attention are recorded for Malmö, Sweden. Age- and sexspecific incidence rate ratios (IRRs) were calculated for the different fracture sites as compared to hip fracture in this population [10]. The estimated IRRs were then applied to the Danish hip fracture IRs, assuming that the age- and sexspecific IRRs were equal in Sweden and Denmark [1]. The IRs of forearm fractures in 2010 have recently been estimated for Denmark [8] using health registry data, which has shown a high validity [11], and these IRs were somewhat higher than the imputed IRs by the IOF [1].

Danish IRs are available for hip [5, 6] and forearm fractures $[7,8]$. However, there are no data on the IRs of other fracture types. It has been shown for forearm fractures that imputation based on data from other countries might underestimate the real IR [8], but this has not been examined for other fracture types. Therefore, the objective of our study was to estimate fracture site-specific IRs for Denmark in 2011 and to compare those to the previously reported imputed data.

\section{Methods}

\section{Source population}

In Denmark, the extensive nature of registers, covering contacts to the health sector, offers good possibilities for studies on the occurrence of fractures [11]. Using the unique 10-digit civil registry number that is assigned to all Danish citizens shortly after birth, a complete hospital discharge history can be established for each individual, and valid linkage between population-based registries can be obtained [12]. Data on all changes in vital status, including change of address and date of death for the entire Danish population has been registered since 1968 in the Civil Registration System. The Danish National Hospital Discharge Register (NHDR) [13] was founded in 1977 and covers all inpatient contacts from 1977 to 1994, and from 1995 furthermore includes all outpatient visits to hospitals, outpatient clinics and emergency rooms. The reliability of Danish national fracture records has shown to be high, with a concordance of $94 \%$ for hip, $84 \%$ for forearm and $83 \%$ for humerus fractures between selfreported and registered fractures in female health professionals [11]. This was not a clinical trial and ethics committee approval was not required.

\section{Study design}

Patients were included when they were diagnosed with a fracture, high or low trauma, in 2011 and aged 20 years or older. Any fracture was determined by the following International Classification of Diseases and Related Health Problems (ICD)-10 codes: S02, S12, S22, S32, S42, S52, S62, S72, S82, S92, T02, T08, T10 and T12. We investigated the following fracture sites: skull (S02), clinical symptomatic vertebral fracture (S12, S22.0, S22.1, S32.0, T08), ribs (S22.2 S22.9), pelvis (S32), clavicle (S42.0), scapula (S42.1), humerus (S42.2-S42.4), forearm (S52), carpal (S62.0, S62.1), hip (S72.0 - S72.2), femur unspecified (S72.3 - S72.9), patella (S82.0), tibia/fibula (S82.1-S82.4), ankle (S82.5, S82.6, S82.8) and foot (S92). Unspecified fracture consisted of all other fracture ICD-10 codes. Major osteoporotic fracture was determined as a hip, humerus, forearm or clinical symptomatic vertebral fracture according to the WHO definition [14]. Hip fracture was further stratified by the location of the fracture: neck, pertrochanteric or subtrochanteric (ICD-10: S72.0, S72.1 and S72.2, respectively). Surgery codes 'KNFB' and 'KNFJ4-9' [15] were used to determine which hip fractures were confirmed by surgery within 10 days after the date of fracture. 
The population demographics of the background population in 2011 were obtained online from Statistics Denmark (www.statistikbanken.dst.dk). IRs (number of fractures/ 10,000 person-years) were calculated by dividing all cases of the first recorded fracture during 2011 over the total number of persons alive on July 1, 2011, and aged 20 or older. To overcome the potential problem of counting the same fracture twice, all fractures with a record of a previous fracture (of the same type or coded as unspecified) in 6 months before the fracture date in 2011 were excluded. Age- and gender-specific IRs were estimated as well as IRs for the above defined fracture sites. Women-to-men IRRs were determined by dividing the women IR over the men IR. For the different fracture types, the first fracture in that specific category was used to calculate the IR.

\section{Results}

The total number of incident fractures in people aged 20 years and older in 2011 was 80,760 (IR 191, $95 \%$ confidence interval (CI) 190-193 per 10,000 person-years (py)), of which 45,362 (56.2 \%, IR 211, $95 \%$ CI 209-213) occurred in women and 35,398 (43.8\%, IR 171, $95 \%$ CI 169-173) in men, Table 1 . The majority of the fractures occurred in the population aged 50 years and older $(n=50,470$, IR 249, $95 \%$ CI 247-251), Table 1 . When patients with a history of a fracture in 6 months before were not excluded, the total number of incident fractures in people aged 50 years and older was $4.5 \%$ higher $(n=52,745)$. Until the age of 50 , fractures occurred more often in men than in women (women to men IRR $0.60 ; 95 \%$ CI $0.59-0.62)$. Whereas after the age of 50 , the majority of the fractures occurred in women (IRR 1.89; $95 \%$ CI 1.85-1.92). Figure 1 shows that the IRs strongly increased in both men and women after age 75 .

The total number of incident of the major osteoporotic fractures was 35,102 of which $82 \%$ occurred in the population aged 50 years and older. Women accounted for two third of the major osteoporotic fractures, and their IR was 2.5 times higher than the IR for men aged 50+, Table 2. Men and women showed a comparable IR until the age of 50, thereafter the IRs started to diverge until the age of 75 (Fig. 2).

The following sites showed homogeneous patterns of fracture IRs with age: femur, hip, humerus, pelvis, clinical symptomatic vertebral, rib, major osteoporotic and any fracture. There was an exponential increase starting at the 50-54 age category (Fig. 2). The IR of forearm fractures yielded a strong increase from the age of 45 years. The IRs of tibia and clavicle fractures started to rise at age 75 . The IRs of carpal, skull and foot fractures (men only) declined with age, whereas the IRs of foot fractures rose in women aged 45-59 years and decreased thereafter. The IR of ankle fractures in men was steady, in contrast to the IR for women, which rose until age
60 and then stabilized. Rib and patella fractures showed a continuous increase for both men and women. Table 2 shows the IRs and total number of fractures in the population aged 50 and older. The women-to-men IRR was highest for forearm fracture (IRR 3.8).

Stratification to hip fracture sites did not result in different patterns, Table 3. The hip fracture IRs strongly increased from age 75 . The IR was higher in women than in men and the majority $(53.5 \%)$ of the hip fractures occurred in the neck of the hip. Table 4 shows the IRs of hip fractures which were confirmed by a surgery in 10 days after the date of fracture; those IRs were about 15 to $20 \%$ lower than the total hip fracture IRs. The same IR pattern was visible as with hip fracture and hip fracture stratified by fracture location.

Our estimated number of fractures for various sites was considerably different to the estimates from the IOF. The number of incident fractures in patients aged 50 years and older (including people with a history of a fracture in 6 months before) was 52,745, 10,488, 13,746 and 2299 in the present study for any hip, forearm and clinical symptomatic vertebral fracture, respectively. The IOF estimate was $25 \%$ higher for any fracture $(N=66,000), 14 \%$ higher for hip fracture $(N=12$, $000)$ and $27 \%$ lower for forearm fracture $(N=10,000)$ [1]. The IOF estimate for clinical symptomatic vertebral fracture was 4.3 times higher $(N=10,000)$ as compared to our results [1].

\section{Discussion}

We have reported age- and gender-specific IRs for different fracture sites in the Danish population aged 20 years and older in 2011. The total number of incident fractures was 80,760. The IRs for any hip, femur, humerus, pelvis, clinical symptomatic vertebral, rib and major osteoporotic fracture increased with age, in contrast to the fractures of the carpus, foot or skull, which declined with age. Until the age of 50, fractures occurred more frequently in men than in women, while this was reversed after the age of 50 .

The pattern of the IRs of forearm fractures of the present study are in line with the results of a study that investigated the IRs of forearm fractures in Denmark in 2010 [6]. Both studies showed a steady IR up to age categories of 44 years and a rise thereafter, especially in women. However, the IRs of forearm fractures in women aged 50 to 79 years were lower (8-21 fractures/10,000 py) in the present study than in the 2010 study, which might be due to random variation and the fact that we excluded patients with an unspecified fracture in 6 months before the date of fracture in 2011 [6]. The results for hip fracture are comparable with earlier results from Denmark, 2008 [4]. Our results are in keeping with results for the Dutch population [16], when considering a threefold difference in hip fracture IRs as shown earlier [17]. As 


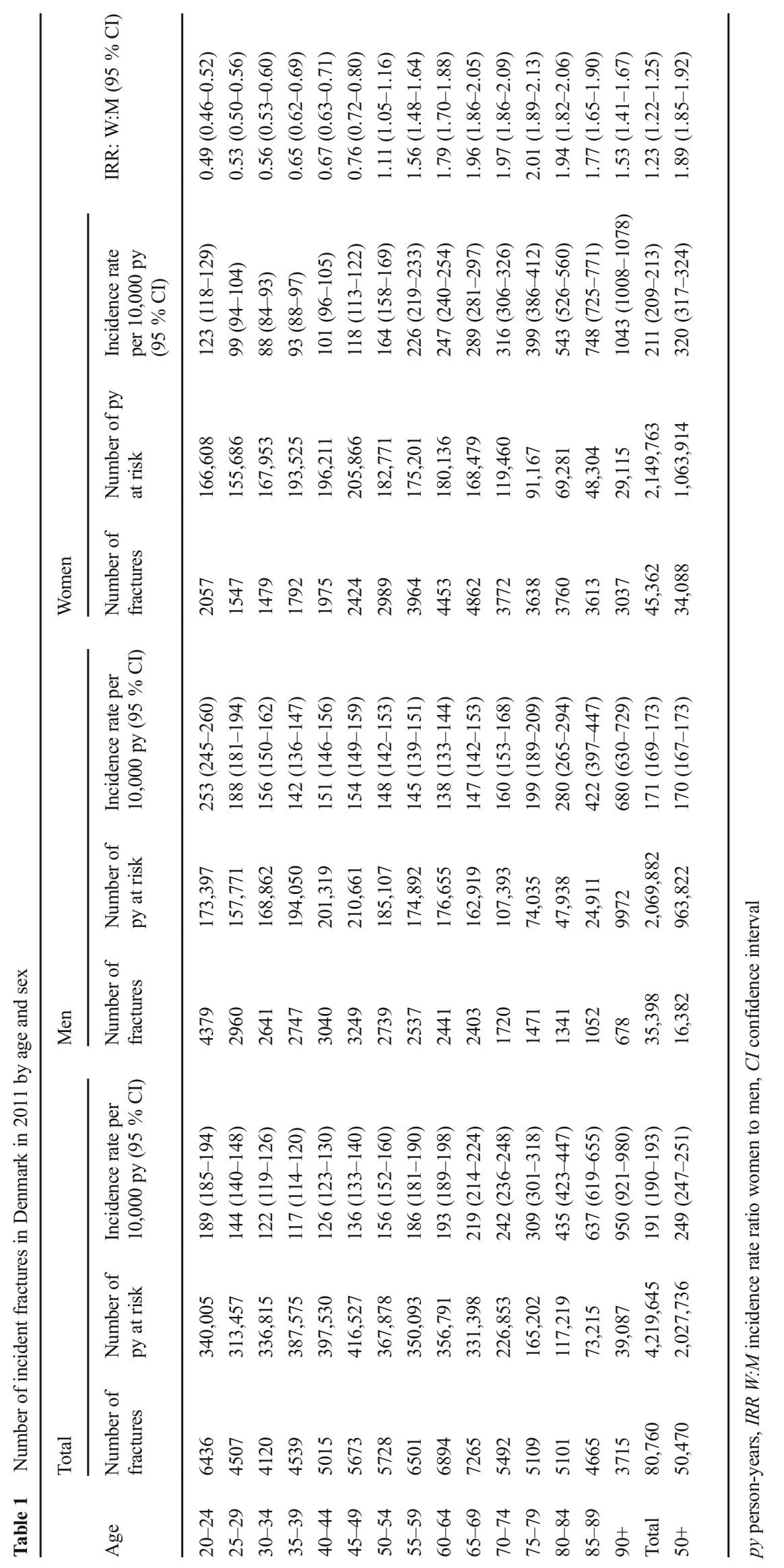




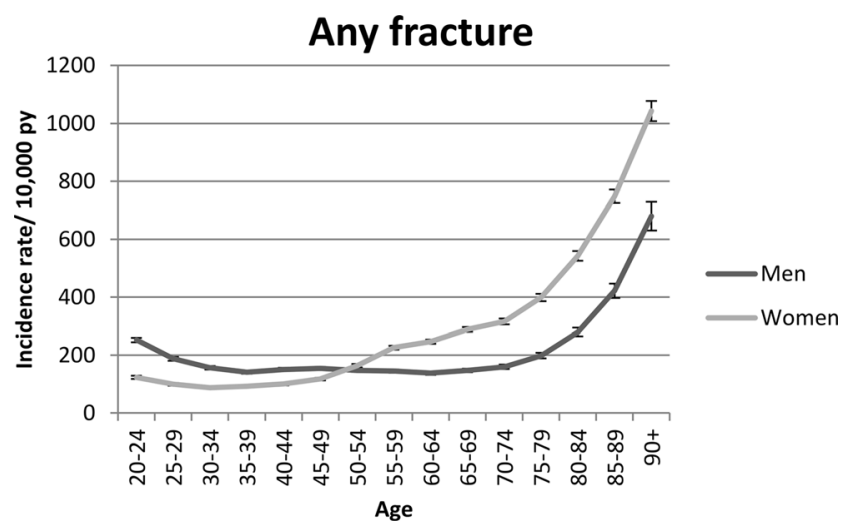

Fig. 1 Incidence rates of the first fracture in 2011 stratified by age and sex. $p y$ person-years

compared to IRs for Norway [18], our results are similar below the age of 80 , whereas our results are lower than the Norwegian IRs for age groups of $\geq 80$. Based on a study which estimated standardized hip fracture rates for different European countries, a higher hip fracture IR for Denmark was expected as compared to Norway [17]. The Norwegian study used data from 1994 to 2008 of a particular city to estimate IRs, while we used data from the whole country of Denmark for 2011 and this might partly explain the differences. Previous studies have demonstrated higher IRs of osteoporotic fractures in urban as compared to rural regions in Norway although this is believed principally to be with regard to forearm fractures $[19,20]$.
The same pattern of IRs (stable until the age of 50 years and a strong rise thereafter) was visible for any fracture, as compared to the results of a study investigating the IRs of different fracture sites in the UK, between 1988 and 1998 [21]. Both studies investigated different fracture sites and those were comparable as well, except for patella and clinical symptomatic vertebral fractures, which showed a different pattern in people aged 80 and over. The IR was about 1.5-2 times higher in Denmark than in the UK, except for rib fracture which showed an equal IR. This may be explained by various reasons, such as differences in the definition of incident fracture between the studies, differences in the studied time period and differences in the used data source. Additionally, it is known from literature that IRs in Scandinavia are about 1.5-2 times higher than those in the rest of Europe [4, 22, 23].

The IOF recently estimated numbers of fractures in 2010 for 27 different EU countries, including Denmark [1]. This is of course helpful for an appraisal of the societal burden, and the report relied on the official statistics as available. Hence, for Denmark, the IOF had only data available on hip fractures, and imputed numbers of other fracture sites using the ratios of hip to other fracture types using Swedish data of Malmö (1987-1994) [10]. The IOF estimates were $25 \%$ higher for any fracture and $14 \%$ for hip fractures as compared to the numbers estimated in the current study. In contrast, the IOF estimate for forearm fractures was $27 \%$ lower than the present number of fractures. This is in line with recent incidence rates of forearm fractures in Denmark in 2010 [6], which used the

Table 2 Incidence rate and total number of fractures stratified by gender and fracture type in people aged 50 years and older

\begin{tabular}{|c|c|c|c|c|c|c|}
\hline \multirow[b]{2}{*}{ Fracture type } & \multicolumn{3}{|c|}{ Incidence rate/10,000 py $(95 \% \mathrm{Cl})$} & \multicolumn{3}{|c|}{ Number of fractures } \\
\hline & Total & Men & Women & Total & Men & Women \\
\hline Ankle & $20.9(20.3-21.5)$ & $14.0(13.2-14.7)$ & $27.1(26.1-28.1)$ & 4234 & 1348 & 2886 \\
\hline Carpal & $6.4(6.0-6.7)$ & $4.8(4.3-5.2)$ & $7.8(7.3-8.4)$ & 1295 & 460 & 834 \\
\hline Clavicle & $8.9(8.5-9.3)$ & $10.4(9.7-11.0)$ & $7.7(7.1-8.2)$ & 1812 & 998 & 814 \\
\hline Femur & $6.1(5.8-6.4)$ & $4.0(3.6-4.4)$ & $8.0(7.5-8.5)$ & 1237 & 385 & 852 \\
\hline Foot & $21.0(20.4-21.6)$ & $14.8(14.0-15.5)$ & $26.6(25.7-27.6)$ & 4257 & 1423 & 2834 \\
\hline Forearm & $65.1(64.0-66.2)$ & $26.0(25.0-27.0)$ & $100.5(98.6-102.4)$ & 13,192 & 2504 & 10,688 \\
\hline Hip & $43.8(42.9-44.7)$ & $29.2(28.1-30.2)$ & $57.1(55.7-58.5)$ & 8884 & 2811 & 6073 \\
\hline Humerus & $29.1(28.3-29.8)$ & $15.9(15.2-16.7)$ & $40.9(39.7-42.2)$ & 5893 & 1537 & 4356 \\
\hline Patella & $3.3(3.0-3.5)$ & $2.2(1.9-2.5)$ & $4.3(3.9-4.7)$ & 666 & 211 & 455 \\
\hline Pelvis & $9.7(9.2-10.1)$ & $5.4(4.9-5.8)$ & $13.6(12.9-14.3)$ & 1962 & 517 & 1445 \\
\hline Rib & $7.7(7.3-8.1)$ & $10.3(9.6-10.9)$ & $5.4(4.9-5.8)$ & 1562 & 991 & 571 \\
\hline Scapula & $1.6(1.4-1.8)$ & $2.0(1.8-2.3)$ & $1.2(1.0-1.4)$ & 320 & 196 & 123 \\
\hline Skull & $7.7(7.3-8.1)$ & $7.5(6.9-8.0)$ & $7.9(7.4-8.4)$ & 1561 & 720 & 841 \\
\hline Tibia & $8.7(8.3-9.1)$ & $6.3(5.8-6.9)$ & $10.8(10.2-11.4)$ & 1761 & 612 & 1149 \\
\hline Clinical symptomatic vertebral & $10.9(10.4-11.3)$ & $10.3(9.6-10.9)$ & $11.4(10.8-12.1)$ & 2204 & 989 & 1215 \\
\hline Major osteoporotic & $142.0(140.3-143.6)$ & $78.4(76.6-80.1)$ & $199.6(196.9-202.2)$ & 28,786 & 7552 & 21,234 \\
\hline
\end{tabular}

py person-year; major osteoporotic hip, forearm, humerus or clinical symptomatic vertebral fracture; $C I$ confidence interval 
Fig. 2 Incidence rates of the first fracture in 2011 stratified by fracture type, age and sex. Major osteoporotic fracture: fracture of the hip, humerus, forearm or vertebrae
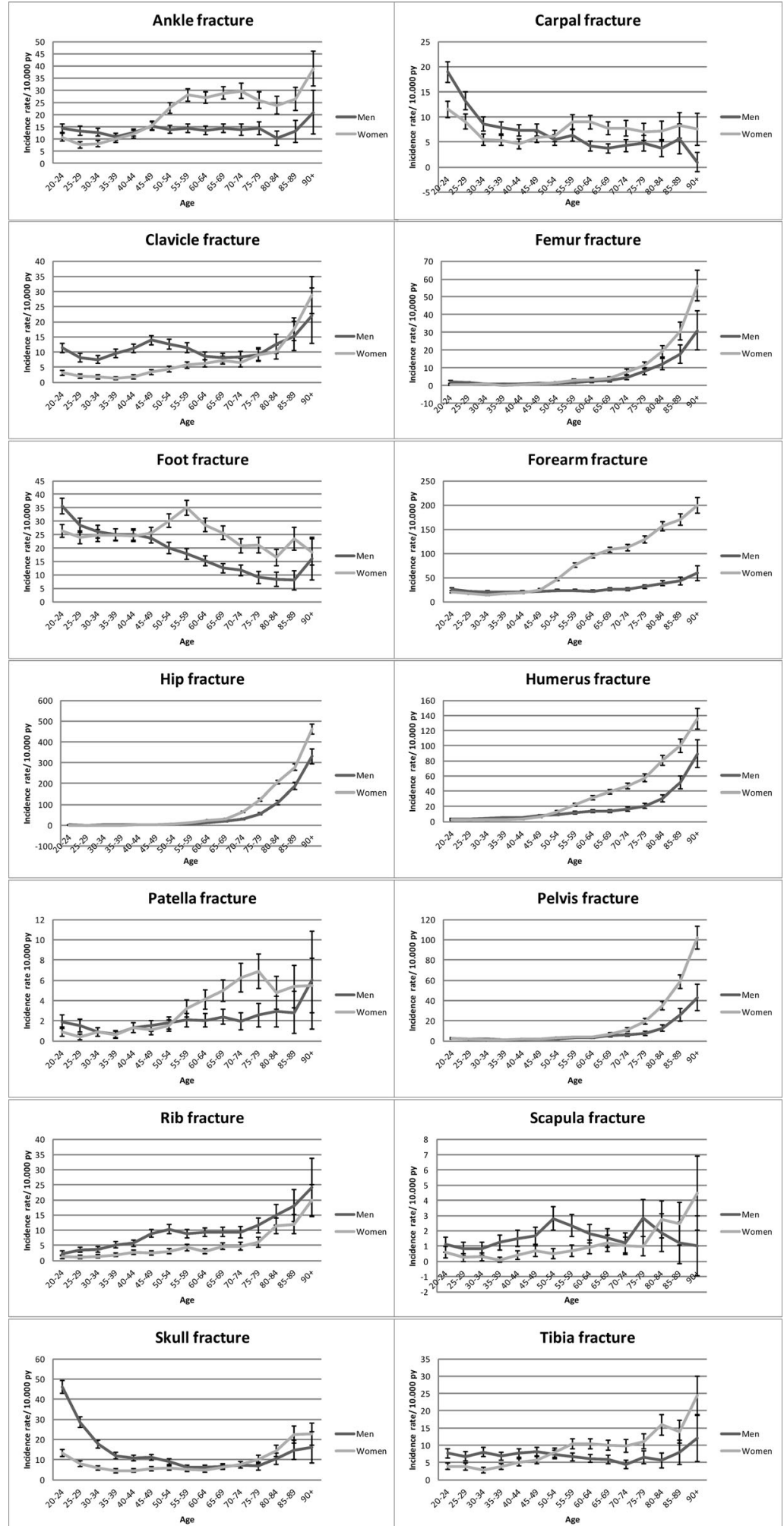

Tibia fracture
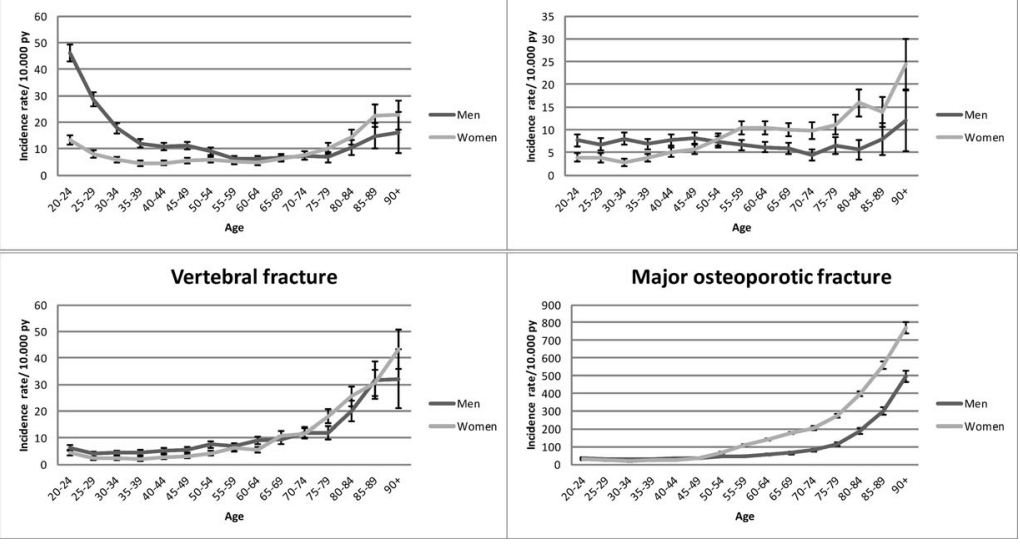
Table 3 Incidence rates/10,000 py for hip fractures in people aged 50 years and older stratified by age, sex and hip fracture type

\begin{tabular}{|c|c|c|c|c|c|c|}
\hline \multirow{3}{*}{$\begin{array}{l}\text { Type of hip fracture } \\
\text { (ICD-10 code) } \\
\text { Age }\end{array}$} & \multicolumn{2}{|l|}{$\begin{array}{l}\text { Neck } \\
\text { (S72.0) }\end{array}$} & \multicolumn{2}{|l|}{$\begin{array}{l}\text { Petrochanteric } \\
\text { (S72.1) }\end{array}$} & \multicolumn{2}{|c|}{$\begin{array}{l}\text { Subtrochanteric } \\
\text { (S72.2) }\end{array}$} \\
\hline & \multicolumn{6}{|c|}{ Hip fracture incidence rates $/ 10,000$ py $(95 \% \mathrm{CI})$} \\
\hline & Men & Women & Men & Women & Men & Women \\
\hline $50-54$ & $3(2-4)$ & $3(2-4)$ & $3(2-4)$ & $3(2-3)$ & $1(0-1)$ & $1(0-1)$ \\
\hline $55-59$ & $4(3-5)$ & $6(5-7)$ & $4(3-4)$ & $3(2-4)$ & $1(0-1)$ & $1(0-1)$ \\
\hline $60-64$ & $7(6-9)$ & $9(7-10)$ & $6(5-7)$ & $9(8-10)$ & $1(1-2)$ & $1(1-2)$ \\
\hline $65-69$ & $11(10-13)$ & $18(16-20)$ & $8(7-10)$ & $13(11-14)$ & $2(2-3)$ & $3(2-4)$ \\
\hline $70-74$ & $18(16-21)$ & $30(27-33)$ & $14(12-16)$ & $27(25-30)$ & $5(4-6)$ & $5(4-6)$ \\
\hline $75-79$ & $35(31-39)$ & $56(51-61)$ & $25(21-28)$ & $56(53-60)$ & $7(5-9)$ & $9(7-11)$ \\
\hline $80-84$ & $68(60-75)$ & $107(100-115)$ & $50(43-56)$ & $97(90-103)$ & $10(7-13)$ & $16(13-19)$ \\
\hline $85-89$ & $122(108-136)$ & $196(184-208)$ & $93(81-105)$ & $140(129-150)$ & $12(7-16)$ & $29(24-34)$ \\
\hline $90+$ & $221(192-249)$ & $282(263-301)$ & $158(134-183)$ & $232(215-249)$ & $25(15-35)$ & $55(46-63)$ \\
\hline
\end{tabular}

py person-years, $C I$ confidence interval

same data source as in this study. The number of clinical symptomatic vertebral fractures estimated by the IOF is about 4.3 times higher as the number of clinical symptomatic vertebral fractures in the present study. The IOF used Swedish ageand sex-specific IRRs from vertebral to hip fracture IRs based on radiography referrals. In the present study, we used register data which especially for clinical vertebral fractures might be less accurate than the radiographic data. As far as we know, there is no data available on how well clinical vertebral fractures are captured in the Danish registry, and, therefore, it is difficult to compare the IOF estimate to the estimate of the present study. When comparing the present data to the data from the IOF, one has to take into account that there are some differences between the studies. The IOF estimated the number of fractures for 2010, based on data from 2004 including repeat admissions [1], while we used data from 2011 and applied a washout period of 6 months. Hip fracture IRs have shown to decline in Denmark [4, 6]. This decline in hip fracture incidence rates and the repeat admissions might explain the overestimation of the number of hip fractures. The imputation of fracture incidence rates might be improved by taking secular trends of fracture incidence rates into account.

This study has several strengths. We were able to estimate the number of fractures in 2011 for the whole country of Denmark. Moreover, we were able to stratify different fracture sites, without imputation based on data from other fracture sites or other countries. This made it also possible to compare our data to estimated IRs based on imputed data. The reliability of Danish national fracture records has previously been addressed in the Danish Nurses Cohort Study $(N=18,800)$, where $94 \%$

Table 4 Incidence rates/10,000 py for hip fractures which were confirmed by surgery in people aged 50 years and older stratified by age, sex and hip fracture type

\begin{tabular}{|c|c|c|c|c|c|c|}
\hline \multirow{3}{*}{$\begin{array}{l}\text { Type of hip fracture } \\
\text { (ICD-10 code) }\end{array}$} & \multicolumn{2}{|l|}{ Neck (S72.0) } & \multicolumn{2}{|c|}{ Petrochanteric (S72.1) } & \multicolumn{2}{|c|}{ Subtrochanteric (S72.2) } \\
\hline & \multicolumn{6}{|c|}{ Hip fractures incidence rates $/ 10,000$ py confirmed by surgery $(95 \% \mathrm{CI})$} \\
\hline & Men & Women & Men & Women & Men & Women \\
\hline $50-54$ & $2(2-3)$ & $2(2-2)$ & $2(1-3)$ & $1(1-1)$ & $1(0-1)$ & $1(0-1)$ \\
\hline $55-59$ & $4(3-5)$ & $4(4-5)$ & $3(2-3)$ & $2(2-3)$ & $1(0-1)$ & $1(0-1)$ \\
\hline $60-64$ & $6(5-7)$ & $7(6-7)$ & $5(4-6)$ & $4(3-4)$ & $1(1-2)$ & $1(1-1)$ \\
\hline $65-69$ & $9(7-10)$ & $15(14-16)$ & $7(6-8)$ & $8(7-9)$ & $2(1-2)$ & $2(2-3)$ \\
\hline $70-74$ & $15(13-17)$ & $25(24-27)$ & $11(9-13)$ & $15(14-16)$ & $4(3-5)$ & $4(3-5)$ \\
\hline $75-79$ & $28(25-31)$ & $47(45-50)$ & $20(17-22)$ & $30(28-32)$ & $5(4-7)$ & $7(6-8)$ \\
\hline $80-84$ & $55(51-60)$ & $89(85-93)$ & $42(38-45)$ & $62(59-66)$ & $9(7-11)$ & $13(11-14)$ \\
\hline $85-89$ & $102(96-108)$ & $162(155-170)$ & $80(75-86)$ & $122(115-128)$ & $8(6-10)$ & $24(22-27)$ \\
\hline $90+$ & $173(165-182)$ & $226(213-238)$ & $128(121-136)$ & $203(191-215)$ & $18(15-21)$ & $47(41-53)$ \\
\hline
\end{tabular}

py person-years, $C I$ confidence interval 
concordance was found between self-reported hip fracture in female health professionals and registered hip fracture, $84 \%$ concordance for forearm fractures and $83 \%$ for humerus fractures [11].

Furthermore, the present results provide more accurate estimates of the number of fractures and, thereby, these data will assist to the planning of health services and to the estimation of fracture-associated costs. And the present estimates could also be used to update the Danish algorithms for Fracture Risk Assessment Tool (FRAX). At present, the Danish version of FRAX included in the major osteoporotic fracture risk estimates a vertebral fracture probability that is imputed from Danish official hip fracture rates using Malmö conversion ratios, while forearm and humerus fractures are those reported by the Danish National Board of Health at the time. The present study has the advantage of using a conservative approach to reduce the risk of multiple counting of the same fracture, or including hip fracture repair, and it is also the most up-to-date incidence rate report. We are aware of some limitations of this study. Our IR estimates might be somewhat conservative, because we excluded all fractures with a history of fracture of the same type in 6 months before, to overcome the problem of double counting of the same fracture. Additionally, we were only able to estimate the number of vertebral fractures that came to clinical attention. This of course reflects the immediate societal burden and use of the healthcare system, but patients with vertebral fractures who do not receive the diagnostic work-up including $\mathrm{x}$-rays are also subject to increased morbidity and mortality [24].

In summary, we have shown age- and gender-specific fracture rates for any fracture as well as for different fracture sites. The IRs of most fracture sites increased with age. Until the age of 50, fractures occurred more in men than in women, while this was reversed in older age groups. Estimating the number of fractures for Denmark based on the imputation of data from other countries led to both over- and underestimation. Future research should therefore focus on how to improve those imputations as not all countries have nationwide registry data.

\section{Compliance with ethical standards}

Conflicts of interest JD and FV declare that they are employed by the Division of Pharmacoepidemiology \& Clinical Pharmacology, which has received unrestricted funding from the Netherlands Organisation for Health Research and Development (ZonMW), the Dutch Health Care Insurance Board (CVZ), the Royal Dutch Pharmacists Association (KNMP), the private-public funded Top Institute Pharma (www. tipharma.nl) (includes co-funding from universities, government and industry), the EU Innovative Medicines Initiative (IMI), the EU 7th Framework Program (FP7) and the Dutch Ministry of Health and Industry (including GlaxoSmithKline, Pfizer, and others). BA reports institutional research contracts with Novartis and prior advisory board membership for Amgen, Merck and Nycomed/Takeda. LH, SAE, HO, $\mathrm{RH}, \mathrm{JB}$ and PV declare no conflicts of interest.

Funding source None
Open Access This article is distributed under the terms of the Creative Commons Attribution-NonCommercial 4.0 International License (http:// creativecommons.org/licenses/by-nc/4.0/), which permits any noncommercial use, distribution, and reproduction in any medium, provided you give appropriate credit to the original author(s) and the source, provide a link to the Creative Commons license, and indicate if changes were made.

\section{References}

1. Svedbom A, Hernlund E, Ivergård M, Compston J, Cooper C, Stenmark J, McCloskey EV, Jönsson B, Abrahamsen B, Kanis JA (2013) Epidemiology and economic burden of osteoporosis in Denmark. Arch Osteoporos 8:137

2. Burge R, Dawson-Hughes B, Solomon DH, Wong JB, King A, Tosteson A (2007) Incidence and economic burden of osteoporosis-related fractures in the United States, 2005-2025. J Bone Miner Res 22(3):465-475

3. Cooper C, Cole ZA, Holroyd CR, Earl SC, Harvey NC, Dennison EM, Melton LJ, Cummings SR, Kanis JA, IOF CSA Working Group on Fracture Epidemiology (2011) Secular trends in the incidence of hip and other osteoporotic fractures. Osteoporos Int 22(5): $1277-1288$

4. Requena G, Abbing-Karahagopian V, Huerta C, De Bruin ML, Alvarez Y, Miret M, Hesse U, Gardarsdottir H, Souverein PC, Slattery J, Schneider C, Rottenkolber M, Schmiedl S, Gil M, De Groot MC, Bate A, Ruigómez A, García Rodríguez LA, Johansson $\mathrm{S}$, de Vries F, Montero D, Schlienger R, Reynolds R, Klungel OH, de Abajo FJ (2014) Incidence rates and trends of hip/femur fractures in five European countries: comparison using e-healthcare records databases. Calcif Tissue Int 94(6):580-589

5. Giversen IM (2006) Time trends of age-adjusted incidence rates of first hip fractures: a register-based study among older people in Viborg County, Denmark, 1987-1997. Osteoporos Int 17(4):552564

6. Abrahamsen B, Vestergaard P (2010) Declining incidence of hip fractures and the extent of use of anti-osteoporotic therapy in Denmark 1997-2006. Osteoporos Int 21(3):373-380

7. Lauritzen JB, Schwarz P, Lund B, McNair P, Transbøl I (1993) Changing incidence and residual lifetime risk of common osteoporosis-related fractures. Osteoporos Int 3(3):127-132

8. Abrahamsen B, Jørgensen NR, Schwarz P (2015) Epidemiology of forearm fractures in adults in Denmark: national age- and genderspecific incidence rates, ratio of forearm to hip fractures, and extent of surgical fracture repair in inpatients and outpatients. Osteoporos Int 26(1):67-76

9. Andersen TF, Madsen M, Jørgensen J, Mellemkjoer L, Olsen JH (1999) The Danish National Hospital Register. A valuable source of data for modern health sciences. Dan Med Bull 46(3):263-268

10. Kanis JA, Johnell O, Oden A, Sembo I, Redlund-Johnell I, Dawson A, De Laet C, Jonsson B (2000) Long-term risk of osteoporotic fracture in Malmö. Osteoporos Int 11(8):669-674

11. Hundrup YA, Høidrup S, Obel EB, Rasmussen NK (2004) The validity of self-reported fractures among Danish female nurses: comparison with fractures registered in the Danish National Hospital Register. Scand J Public Health 32(2):136-143

12. Frank L (2000) Epidemiology. When an entire country is a cohort. Science 287:2398-2399

13. Andersen T, Madsen M, Jørgensen J, Mellemkjær L, Olsen J (1999) The Danish National Hospital Register. Dan Med Bull 46:263-268

14. FRAX. WHO Fracture risk assessment tool. 2001. shef.ac.uk. www.shef.ac.uk/FRAX/index.aspx 
15. http://www.nip.dk/files/Subsites/NIP/Hoften $\%$ C3\%A6re $\%$ 20 frakturer/2010_Datadefinitioner_g\%C3\%A61010310.pdf. Assessed at 1-7-2015

16. Lalmohamed A, Welsing PM, Lems WF, Jacobs JW, Kanis JA, Johansson H, De Boer A, De Vries F (2012) Calibration of FRAX ${ }^{\circledR} 3.1$ to the Dutch population with data on the epidemiology of hip fractures. Osteoporos Int 23(3):861-869

17. Kanis JA, Odén A, McCloskey EV, Johansson H, Wahl DA, Cooper C, IOF Working Group on Epidemiology and Quality of Life (2012) A systematic review of hip fracture incidence and probability of fracture worldwide. Osteoporos Int 23(9):2239-2256

18. Emaus N, Olsen LR, Ahmed LA, Balteskard L, Jacobsen BK, Magnus T, Ytterstad B (2011) Hip fractures in a city in northern Norway over 15 years: time trends, seasonal variation and mortality: the Harstad Injury Prevention Study. Osteoporos Int 22(10):2603-2610

19. Omsland TK, Ahmed LA, Grønskag A, Schei B, Emaus N, Langhammer A, Joakimsen RM, Jørgensen L, Søgaard AJ, Gjesdal CG, Meyer HE (2011) More forearm fractures among urban than rural women: the NOREPOS study based on the Tromsø study and the HUNT study. J Bone Miner Res 26(4):850-856

20. Diamantopoulos AP, Rohde G, Johnsrud I, Skoie IM, Johnsen V, Hochberg M, Haugeberg G (2012) Incidence rates of fragility hip fracture in middle-aged and elderly men and women in southern Norway. Age Ageing 41(1):86-92

21. van Staa TP, Dennison EM, Leufkens HG, Cooper C (2001) Epidemiology of fractures in England and Wales. Bone 29(6): $517-522$

22. Wade SW, Strader C, Fitzpatrick LA, Anthony MS (2012) Sex- and age-specific incidence of non-traumatic fractures in selected industrialized countries. Arch Osteoporos 7:219-227

23. Hernlund $\mathrm{E}$, Svedbom A, Ivergård $\mathrm{M}$, Compston J, Cooper $\mathrm{C}$, Stenmark J, McCloskey EV, Jönsson B, Kanis JA (2013) Osteoporosis in the European Union: medical management, epidemiology and economic burden. A report prepared in collaboration with the International Osteoporosis Foundation (IOF) and the European Federation of Pharmaceutical Industry Associations (EFPIA). Arch Osteoporos 8:136

24. Hasserius R, Karlsson MK, Nilsson BE, Redlund-Johnell I, Johnell O, European Vertebral Osteoporosis Study (2003) Prevalent vertebral deformities predict increased mortality and increased fracture rate in both men and women: a 10year population-based study of 598 individuals from the Swedish cohort in the European Vertebral Osteoporosis Study. Osteoporos Int 14(1):61-68 